\title{
The effect of histamine on kidney by fasting in rats
}

\author{
Gurgen $\mathrm{SG}^{1}$, Erdogan $\mathrm{D}^{2}$, Take Kaplanoglu $\mathrm{G}^{2}$ \\ Department of Histology and Embryology, School of Vocational Health Service, Celal Bayar University, \\ Manisa, Turkey. serengurgen@yahoo.com
}

\begin{abstract}
Background: The aim of this study was to investigate ultrastructural and apoptotic changes occurring in the kidneys in fasting individuals and to examine the effects of histamine treatment at the electron-microscopic and immunohistochemical levels.

Methods: Eighteen adult Wistar male rats were randomly divided into three groups ( $\mathrm{n}=6$ for each). Control group (1), fasting group (12 h) (2), and fasting+histamine injection $(0.5 \mathrm{mg} / \mathrm{kg})(3)$ group. Expression of caspase-3 and caspase- 9 was determined in the tissue sections using immunohistochemical techniques. Quantitative data were obtained using H-SCORE, and statistical evaluations were then performed. The ultrastructure of the kidney tissues was examined using transmission electron microscopy.

Results: Weak caspase- 3 and caspase- 9 expression was observed in the renal tubules and glomeruli in the control group, while immunoreactivity was more intense in the fasting group $(p<0.05)$. In the fasting+histamine group, caspase- 3 and caspase- 9 immunostaining was significantly positive in both renal tubules and glomeruli $(p<0.05)$. At electron microscopic evaluation, degenerative changes were seen in the glomeruli of the fasting group, as well as partial vacuolization and disruption at the basal foldings in the tubular epithelial cells. In the fasting+histamine group, in addition to significant dilatation of all glomerular capillaries, there were degenerative changes in all tubular and canalicular epithelial cells in the proximal tubules.

Conclusions: Fasting, an important metabolic stress factor, accompanied by histamine treatment may cause significant disruptions in the kidneys, particularly in the glomerular capillaries and proximal and distal tubules (Tab. 1, Fig. 2, Ref. 34). Full Text in PDF www.elis.sk.

Key words: histamine, fasting, kidney, Immunohistochemistry, electron microscopy.
\end{abstract}

Histamine is an important amino acid that reduces blood pressure through intense vasodilatation of blood vessels. It also increases capillary permeability and removes excess plasma from the vessels, causing edema and hypovolemia $(1,2,3)$.

Histamine is produced by the enzyme histidine decarboxylase (HDC). Although the highest activity of HDC and histamine content have been detected in mast cells and basophils, the major sources of histamine in immunological reactions are the tissues, and these have therefore been the subject of the majority of studies $(4,5,6)$. These findings raise the possibility that, in addition to being a primary mediator in allergic and inflammatory processes, histamine may also have important functions in the regulation of basic cellular biological processes (7). The importance of histamine has been demonstrated in gastric acid secretion, contraction of smooth muscle, neurotransmission, wound repair, embryogenesis, hematopoiesis, allergic skin reactions and malignant growths. Additionally, histamine has been found to function in the auto,

${ }^{1}$ Department of Histology and Embryology, School of Vocational Health Service, Celal Bayar University, Manisa, Turkey, and ${ }^{2}$ Department of Histology and Embryology, Gazi University Faculty of Medicine, Ankara, Turkey

Address for correspondence: S.G. Gurgen, $\mathrm{PhD}$, Celal Bayar University School of Vocational Health Service, Uncubozköy, Manisa, Turkey Phone: +90.236.2371378, Fax: +90.236.2348931

Acknowledgements: We confirm that we have read the Journal's position on issues involved in ethical publication and affirm that this report is consistent with those guidelines. para and endocrine pathways through four types of histamine receptors $(\mathrm{H} 1, \mathrm{H} 2, \mathrm{H} 3$ and $\mathrm{H} 4)$, while also signaling via different signal-transduction pathways $(8,9,10,11)$. Histamine has also been shown to enhance $\mathrm{Ca}^{++}$entry into several tissues, including vascular endothelium, bronchial smooth muscles, brain and kidneys $(4,5,6,12)$. Previous studies have suggested that kidney tissue, particularly the renal cortex, contains an appreciable amount of histamine (13). In a general histochemical survey on monkey tissues, histamine was detected in the glomerular capillaries (14). Histidine decarboxylase, the key enzyme in histamine biosynthesis, was found in the glomeruli of rat the kidney, suggesting that glomeruli may be a site of intrarenal histamine formation (15).

Kidneys play an important role in the maintenance of plasma glucose levels and acid-base balance during fasting. Fasting is associated with protein deprivation, which has been shown to alter urinary concentrating ability in both humans and experimental animals $(16,17)$. During the process of adaptation to fasting, the kidneys are thought to be responsible for proteolysis of endogenic-proteins as the first stage of their reconstruction. This function is performed by structural-functional reconstruction of the juxtaglomerular complex, the vessels of the filtration apparatus, and by the proteolytic system in the proximal part of the nephron canaliculus (18).

Apoptosis is an active mechanism of cell clearance and is presumed to be involved in the progression of kidney injury in several animal models (19). One of the major multigene families involved in the molecular controls of cell death is the caspase gene family. 
Caspases are a family of cysteine proteases that are activated during programmed cell death. Over 40 substrates have been identified for caspases, whose cleavage can be either an activating or inactivating event for the functioning of the protein. Initiator caspases $(-8,-9,-10)$ activate effector caspases $(-3,-6,-7)$. Effector caspases can, in turn, activate initiator caspases (20). Caspases participate in two distinct signaling pathways: activation of proinflammatory cytokines and promotion of apoptotic and necrotic cell death. One such, caspase-3 (CPP32/Yama/apopain) is an executor of apoptosis $(21,22)$. Loss of renal parenchymal cells by apoptosis and the involvement of caspase- 3 have been reported to play important roles in the progression of chronic allograft nephropathy (23).

Although there have been histopathological and biochemical studies that discuss the separate effects of fasting and histamine on the kidneys, we encountered no studies in the literature that combine both aspects of their effects on the kidneys $(8,12$, $16,18)$. In this context, we hypothesized that the effects of histamine and fasting on the kidneys are associated with apoptotic cell death. We evaluated the degenerative effect of histamine in an established animal model in which rats were fasted and treated with histamine and demonstrated its ultrastructural and immunohistochemical features.

\section{Material and methods}

\section{Animals}

Eighteen adult Wistar male rats with average weight of $250 \mathrm{~g}$ were divided into three groups. The rats were kept at $21-23{ }^{\circ} \mathrm{C}$ and under a 12-h light:12-h dark schedule in the Laboratory Animal Research Center at Gazi University. The animals were permitted access to standard rodent chow and purified water ad libitum. All animal experiments were carried out in accordance with the European Communities Council Directive of 24 November 1986 (86/609/EEC) and were approved by the Animal Care Committee of Gazi University.

\section{Experimental protocol}

The first, control group was kept intact during the whole procedure $(n=6)$. The second group did not consume any histamine during the $12 \mathrm{~h}$ of fasting $(\mathrm{n}=6)$, while the third group was administered $0.5 \mathrm{mg} / \mathrm{kg}$ exogenous histamine intraperitoneally during the $12 \mathrm{~h}$ of fasting $(\mathrm{n}=6)$. The rats were decapitated under pentobarbital anesthesia $1 \mathrm{~h}$ after histamine administration. Kidney tissues from each group were fixed in neutral formalin for $72 \mathrm{~h}$ and processed for paraffin embedding. Sections $4-5 \mathrm{~mm}$ thick were processed for polysine microscope slides.

\section{Immunohistochemical procedures}

Slides for immunohistochemical examination were stored in a microwave oven in $0.01 \mathrm{M}$ Tris- $\mathrm{HCl}$ buffer, (LabVision, USA). Endogenous peroxidase activity was blocked in 3\% hydrogen peroxide (LabVision, USA). Epitopes were stabilized by the application of serum blocking solution (LabVision, USA). The slides were then incubated with caspase-3 (rabbit polyclonal antibody Ab-4, 1mg/ml, NeoMarker, USA) and caspase-9 (rabbit polyclonal antibody Ab-6, 1mg/ml, NeoMarker, USA) for $60 \mathrm{~min}$ at room temperature. This was followed up with application of biotinated secondary antibody (Goat anti rabbit, LabVision, USA). Streptavidin peroxidase (Lab Vision, USA) was then applied to the slides. The chromogen used was 3-amino-9-ethylcarbazole (Lab Vision, USA). The slides were subsequently counterstained with Mayer's hematoxylin.

\section{Analyses}

The slides were visualized, and were images obtained using a photolight microscope (CX31 Olympus, Germany) attached to a digital camera (C-5060 Olympus, Germany). Immunohistochemical analysis was performed on kidney cross-sections for all animals using image-analyzing software (Leica Q Win V3 Plus Image).

Two independent observers blind to the treatment regimen performed separate immunolabeling score evaluations. Labeling intensity was graded semi-quantitatively, and the HSCORE was calculated using the equation HSCORE $=\Sigma P i(i+1)$, where $i$ is the intensity of labeling with a value of 1,2 or 3 (weak, moderate or strong, respectively) and $P i$ is the percentage of labeled epithelial cells for each intensity, ranging from $0 \%$ to $100 \%$ (24). Statistical differences were calculated using the Mann-Whitney $U$ test. Results were expressed as mean \pm SD. $p<0.05$ was considered significant.

\section{Electron microscopic procedures}

For electron microscopic examination, tissues from all groups were fixed for $2-3 \mathrm{~h}$ in phosphate-buffer containing $2.5 \%$ gluteraldehyde. They were then post-fixed in $1 \%$ osmium tetraoxide $\left(\mathrm{OsO}_{4}\right)$, followed by dehydration in a series of graded alcohols $(50,60,70,80,90,96$, and $100 \%$ ethanol). After passing through

Tab. 1. HSCORE values of caspase-3 and caspase-9 in control, fasting and fasting+histamine group.

\begin{tabular}{|c|c|c|c|c|}
\hline & Caspase-3 & $\mathrm{p}$ & Caspase-9 & $\mathrm{p}$ \\
\hline Control Glomerular Epithelial Cell & $25.20 \pm 1.30^{\mathrm{ab}}$ & $0.002 *$ & $25.00 \pm 1.58^{\text {gh }}$ & $0.002 *$ \\
\hline Fasting Glomerular Epithelial Cell & $243.20 \pm 3.34$ ac & & $155.40 \pm 2.51^{\mathrm{g} 1}$ & \\
\hline Fasting + Histamine Glomerular Epithelial Cell & $286.40 \pm 4.56^{\mathrm{bc}}$ & & $169.40 \pm 6.84^{\mathrm{h}}$ & \\
\hline Control Distal Tubule Epithelial Cell & $67.60 \pm 1.67 \mathrm{de}$ & $0.002 *$ & $65.60 \pm 1.67 \mathrm{ij}$ & $0.002 *$ \\
\hline Fasting Distal Tubule Epithelial Cell & $164.40 \pm 2.51 \mathrm{df}$ & & $241.60 \pm 4.56^{\text {ih }}$ & \\
\hline Fasting + Histamine Distal Tubule Epithelial Cell & $288.80 \pm 3.34{ }^{\text {ef }}$ & & $290.80 \pm 2.68^{\mathrm{jh}}$ & \\
\hline
\end{tabular}

*Kruskall-Wallis Test $\mathrm{p}$ value, ${ }^{\mathrm{a}}$ Mann-Whitney U Test $\mathrm{z}=-2.63 \mathrm{p}=0.008,{ }^{\mathrm{b}}$ Mann-Whitney U Test $\mathrm{z}=-2.62 \mathrm{p}=0.009,{ }^{\mathrm{c}}$ Mann-Whitney U Test $\mathrm{z}=-2.63 \mathrm{p}=0.008,{ }^{\mathrm{d}}$ MannWhitney U Test $\mathrm{z}=-2.64 \mathrm{p}=0.008$, ${ }^{\mathrm{e}}$ Mann-Whitney U Test $\mathrm{z}=-2.64 \mathrm{p}=0.008,{ }^{\mathrm{f}}$ Mann-Whitney U Test $\mathrm{z}=-2.63 \mathrm{p}=0.008,{ }^{\mathrm{g}} \mathrm{Mann}-\mathrm{Whitney} \mathrm{U}$ Test $\mathrm{z}=-2.64 \mathrm{p}=0.008,{ }^{\mathrm{h}} \mathrm{Mann}-$ Whitney U Test $\mathrm{z}=-2.64 \mathrm{p}=0.008,{ }^{\mathrm{i}}$ Mann-Whitney U Test $\mathrm{z}=-2.64 \mathrm{p}=0.008,{ }^{\mathrm{i}}$ Mann-Whitney U Test $\mathrm{z}=-2.63 \mathrm{p}=0.008,{ }^{\mathrm{j}}$ Mann-Whitney $\mathrm{U}$ Test $\mathrm{z}=-2.64 \mathrm{p}=0.008$, ${ }^{\mathrm{h}} \mathrm{Mann}-$ Whitney U Test $\mathrm{z}=-2.63 \mathrm{p}=0.008$ 

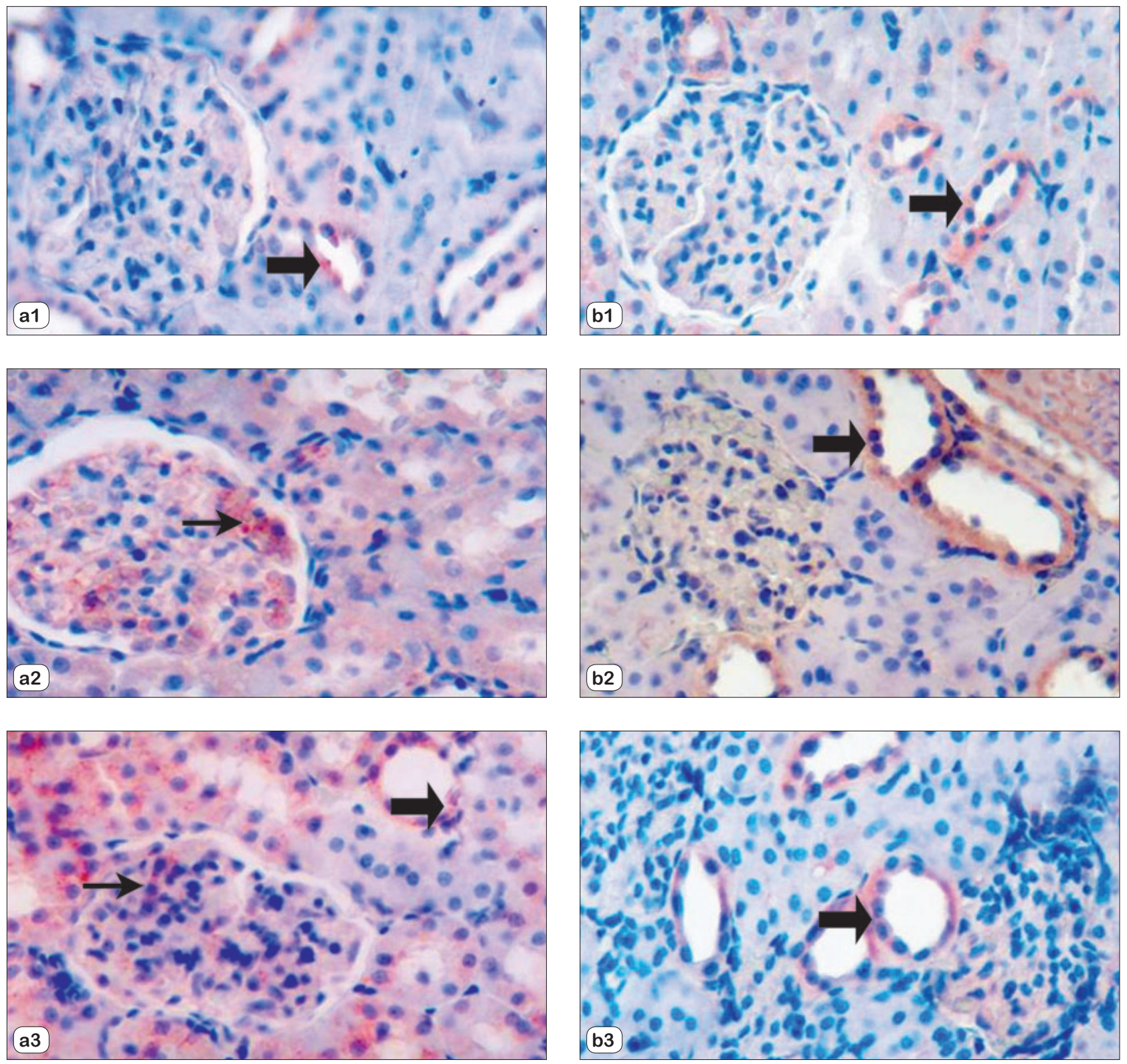

Fig. 1. Immunoreactivity of caspase-3 (a) and caspase-9 (b) in control (1), fasting (2), fasting+histamine (3) group in the kidney. $\Rightarrow$ : distal tubule epithelial cells, $\rightarrow$ : glomerulus. X400.

propylene oxide, the specimens were embedded in an Araldite CY 212 kit. After the selection of appropriate specimens, thin sections were cut and stained with uranyl acetate and lead citrate. These were then examined under an electron microscope (Carl Zeiss EM 900, Germany).

\section{Results}

\section{Immunohistochemical findings}

The distribution pattern of caspase- 3 and caspase-9 HSCORES in the control, fasting and fasting+histamine group kidneys are summarized in Table 1.
In the control group, there was a weak caspase- 3 or caspase- 9 expression in the distal tubules (Figs $1 \mathrm{a} 1,1 \mathrm{~b} 1 ; \mathrm{p}>0.05$ ). Immunoreactivity was detected, especially at the apical cytoplasm of the distal tubule epithelial cells. Additionally, there was no reactivity in the glomeruli (Figs 1a1, 1b1; $<<0.05$ ). In the fasting group, there was an increase in caspase-3 expression in the glomeruli (Fig. 1a2), whereas with caspase-9, immunostaining was weak to moderate in glomerular epithelial cells and strong in distal tubule epithelial cells (Fig. 1b2). Increased caspase-3 reactivity was observed in the fasting+histamine group. There were statistically significant differences in immunolabeling intensities of caspase- 3 between the fasting+histamine and control groups $(p<0.05)$. Caspase- 3 

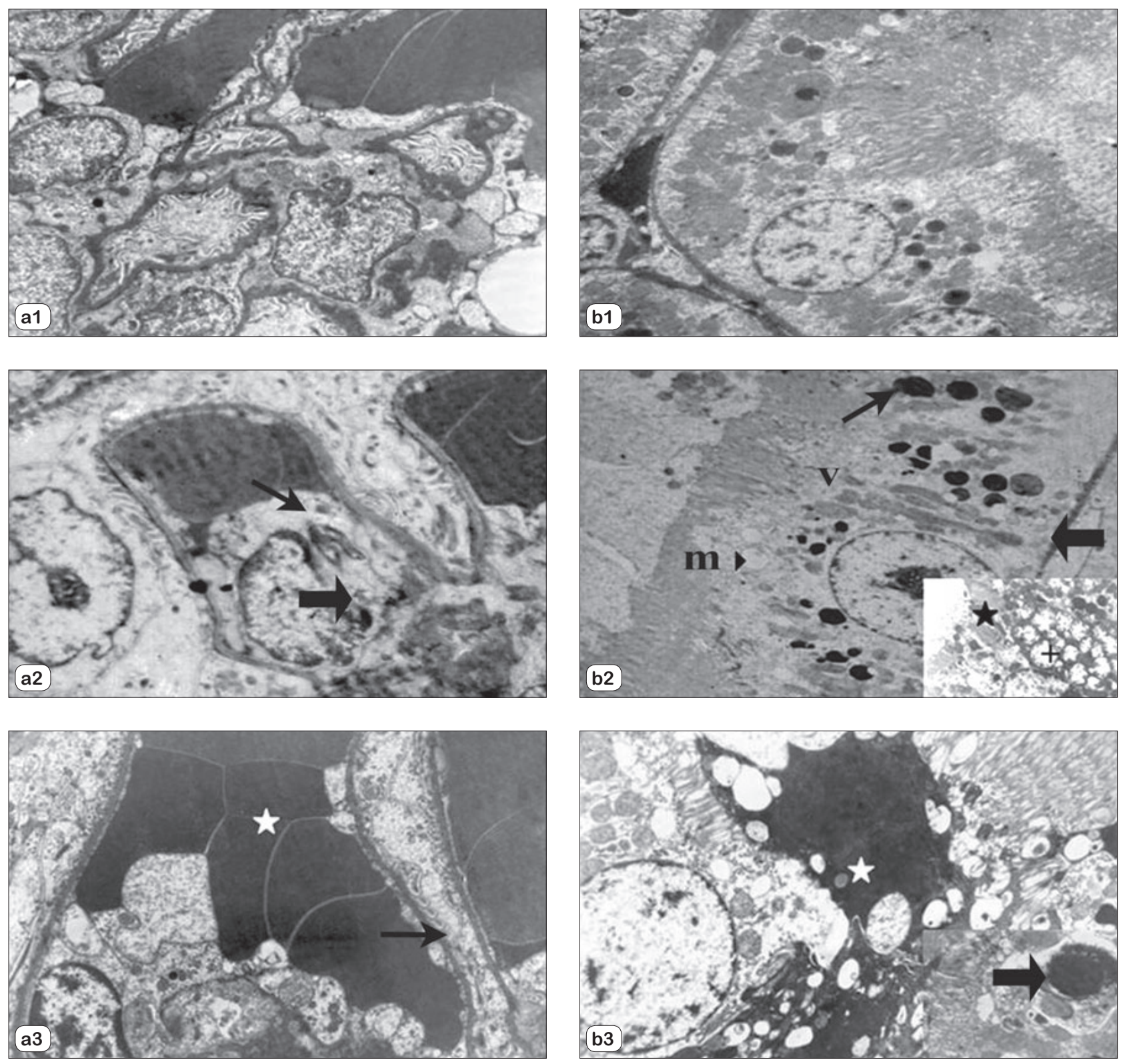

Fig. 2. Electron micrograph of the control (1), fasting (2), fasting+histamine (3) group in the kidney and glumerular capillary (a), proximal tubule (b) $\rightarrow$ : pinocytotic vesicles, $\Rightarrow$ : cristolysis of mitochondria (a2). $\rightarrow$ : Electron-dense lysosomes. $\Rightarrow$ : rarely disappeared basal foldings, m: microvilli, intraglomerular mesangial cells (a1) and proximal tubule (b1) in the control group. v: endostatic vesicles, : large and small vacuoles. Inset: $\star$ : Electron-dense lysosymes, $+:$ swelling, and cristolysis seen in mitochondria (b2) in the fasting group. $\rightarrow$ : Foot process of the podocytes (a3). $\star$ : dilatation in glomerular capillaries. Apoptotic bodies. İnset: $\Rightarrow$ : apoptotic bodies in certain cells. (b3) in the fasting+histamine group. (Uranyl acetate-Lead citrate X3000).

expression at the glomerular epithelial cells and tubule epithelial cells was significantly cytoplasmic and granular in form (Fig. 1a3). There was weak to moderate caspase- 9 expression in the glomerular epithelial cells and strong expression in distal tubule cells in this group (Fig. 1b3). Cytoplasmic expression constantly increased in the distal tubule epithelial cells. Immunolabeling intensities of caspase- 9 in distal tubule cells of the kidney were significantly higher in the fasting+histamine group compared to the control group $(\mathrm{p}<0.05)$.

\section{Electron microscopic findings}

In the control group, glomerular basement membrane (GBM), podocytes, and their foot processes and intraglomerular mesangial cells were normal in structure (Figure 2a1). Proximal tubule basal folds and mitochondria were normal. Few peroxisomes were seen in the cytoplasm. Microvilli were also normal (Fig. 2b1). In the fasting group, glomeruli were generally normal in structure (data not shown). However, high magnification microscopic examinations of glomeruli revealed increases in 
pinocytotic vesicles and cristolysis of mitochondria in some regions of the endothelial cells of capillary loops (Fig. 2a2). The most significant change was the intra-cytoplasmic edema at the apical site of the proximal tubules. An increase in electron-dense lysosomes in cells was also observed. While the regularity of basal foldings was disordered in patches, microvilli had a normal structure. However, an increase in endostatic vesicles and large and small vacuoles enclosed by membranes in apical cytoplasm were observed. Myelin figures were rare in these vacuoles (Fig. $2 \mathrm{~b} 2$ ). Intense degenerative changes were also detected in the epithelial cells of certain tubules. Cytoplasm of these cells was electron-dense, and swelling and cristolysis were present in their mitochondria (Fig. $2 \mathrm{~b} 2$ inset). In the fasting+histamine group, there were significant dilatations in all the glomerular capillaries. In some regions, disappearance or effacement was seen in the foot processes of podocytes (Fig. 2a3). There were significant degenerative changes in all tubular epithelial cells, particularly in the proximal tubules. In some of these tubular epithelial cells, there were large apoptotic bodies in the cytoplasm (Fig. 2b3). Apoptotic cells were displaced from the lumen in some tubules, and microvilli had disappeared in this region (Fig. 2 b3 inset). Certain cells with nuclei were also observed to have become apoptotic bodies.

\section{Discussion}

Recent in vivo and in vitro studies have shown that renal glomeruli actively participate in the regulation of glomerular microcirculation under physiological conditions or in the course of renal injury. It is well recognized that the renal glomerulus is a target organ for a number of circulating hormones and locally synthesized compounds with potent biological activity $(25,26)$.

Fasting generally reduces the baseline metabolism and turnover of materials in the body. Fasting or dietary protein intake also accelerates the nephropathy associated with experimental diabetes, hypertension and systemic lupus (27). In addition, intake of food and water can alter the general metabolic activity of the body in such a way as to affect the metabolism of drugs, including their distribution, movement, retention, and excretion. Our aim was therefore to investigate the uptake, distribution and retention of intraperitoneally administered histamine with special reference to the effects of fasting.

Although several studies have been conducted on experimental fasting or restriction of food, only one examined the effect of fasting on the ultrastructure of the kidney ${ }^{18}$. Gonthmakher et al. carried out observations on degranulation of the myoepithelial cells of the juxtaglomerular complex and dilated lumen of glomerular capillaries and afferent arterioles in the cortex of the rat kidney during fasting. They concluded that this is the kidney's adaptation to fasting to ensure proteolysis of endogenic proteins (18). In another study, they observed hypergranulation and loss in ER and the collapse of glomerular capillaries of the myoepithelial cells of the juxtaglomerular complex in hyperplasia. Accumulation of secretory granules in the myoepithelial cells is combined with the loss of functional activity of the protein synthesizing cells, which indicates a hypofunction in the juxtaglomerular complex (28). They concluded that during fasting a decrease occurs in renin synthesis and secretion in the juxtaglomerular complex. The functional condition of the juxtaglomerular complex plays a key role in the regulation of glomerular hemodynamics. Glomerular hemodynamic changes are an indirect factor for the dilatation and collapse of capillaries. We identified an increase in pinocytotic vesicles and cristolysis of mitochondria in glomeruli and in the number of pale apical vacuoles during fasting. Intense degenerative changes were also detected in the epithelial cells of proximal tubules. Cytoplasms of these cells were electron-dense, and there was swelling and cristolysis in their mitochondria. As evidence of this, strong reabsorption and proteolysis at the proximal tubules are important factors in fasting for facilitating the infiltration of proteins from the glomerular filtration membrane. Protein adaptation is an important physiological mechanism necessary for regulation in protein distribution during fasting. This function is related to the changes in the juxtaglomerular complex and filtration capillaries maintained by the proteolytic system of the proximal tubules.

Caspase- 3 staining has been reported to be closely correlated with the changes in apoptosis, and both have been positively correlated with renal structure and function (29). Yang et al. reported that caspase-3 was strongly expressed in the distal renal tubular cells, suggesting that cell degeneration, necrosis and apoptosis coexist in the tubular epithelial cells in renal tubular damage induced by endotoxin and hypoxia; degeneration and necrosis occur primarily in the proximal tubular epithelial cells, while apoptosis was pronounced in the distal renal cells (26). At immunohistochemical examination, we observed moderate caspase-3 and caspase-9 immunoreactivity in distal tubules in the control group. This confirmed the hypothesis that as kidney tubules continuously undergo regeneration, it is reasonable to assume that apoptosis will also be present in normal kidneys. On the other hand, we detected an increase in caspase- 3 immunoreactivity in the glomerular epithelium and caspase- 9 immunoreactivity in the distal tubules in the fasting group. This indicates that caspase- 9 initiated apoptosis in tubules and caspase- 3 maintained this, especially in the glomeruli. These data confirm that caspase- 3 and caspase- 9 immunoreactivity was greater in glomeruli and tubules compared to the control group.

The role of histamine in the kidney during fasting has not been investigated histologically. Various studies have examined the effects of histamine and protein diet in several tissues with biochemical and cell culture techniques. Bourgoignie et al. showed that dogs fed a low-protein diet developed proteinuria, glomerular sclerosis and showed a decrease in glomerular filtration rate after renal mass reduction (30). Another study showed that histamine affects membrane voltage, ion conductance and ion channels of human glomerular epithelial cells in culture (12).

Histamine is a renal autacoid synthesized in rat and human glomeruli. It has also been shown to affect glomerular metabolism in vitro and renal hemodynamics, including glomerular microcirculation, in vivo $(2,3,26,31)$. Studies using labeled histamine 
$\mathrm{HI}$ and $\mathrm{H} 2$ receptor antagonists have shown that both receptors are present in glomeruli, and that a hormone-sensitive adenylate cyclase primarily linked to the $\mathrm{H} 2$ receptor is present in glomerular cells $(10,11,32)$. More recently, histamine has been shown to stimulate renin release by isolated perfused rat kidneys, an effect primarily mediated by an $\mathrm{H} 2$ receptor $(10,11,33)$. In addition to its hemodynamic effects on the renal and other regional circulations, histamine is an important regulator of the immune-inflammatory response in many tissues (34).

Histamine has important physiological functions in the glomerulus. It dilates renal vasculature and reduces the ultrafiltration quantity (31). Histamine is usually associated with mast cells in almost all tissues and is also produced in the glomerulus and endothelial cells, which modulate contraction in rat mesangial cells $(26,32)$. These findings show that histamine potentially influences glomerular hemodynamics via mesangial cell contraction and further support the hypothesis that the contractile property of the mesangial cell is the underlying mechanism responsible for the reduction in glomerular capillary surface area. However, the relationship between enhanced apoptosis and actions of histamine in kidney tissues has not been established.

Our present findings are that the increased caspase- 3 activity in cortical tubules, especially in distal tubules, is responsive to fasting+histamine treatment. Our observations suggest that, following histamine treatment, there is an increase in proteolysis in the distal tubules, which also affect glomerular filtration, which signals an increase in expression of caspase- 3 thereby causing certain cells with nuclei to become apoptotic bodies. It is likely that fasting+histamine treatment with increased intratubular apoptosis may modulate glomerular functions and other cellular and metabolic processes in glomeruli. Furthermore, we demonstrated that there was moderate caspase-3 staining in glomerular epithelial cells. At electron microscopic evaluation, significant dilatation of all glomerular capillaries was observed. In some regions, foot processes of podocytes had disappeared. These findings indicate they are effects of histamine in glomeruli and are compatible with the possibility that histamine is involved in the regulation of glomerular function and may be influenced by the reconstruction of glomerular filtration.

While we could not identify the mechanisms by which fasting increases the effects of histamine, we can exclude the possibility that increased apoptosis in the kidneys of fasting rats is associated with histamine treatment compared to rats given normal food.

We conclude that fasting is an important metabolic stress factor and, when accompanied by histamine treatment, it is likely to cause prominent disruptions in the kidneys, mainly in the glomerular capillaries and renal tubules. Immunohistochemistry results emphasize the importance of the caspase- 3 and caspase- 9 signaling pathways in the degenerative effects of fasting+histamine characterization of apoptosis mechanisms in the kidneys, especially in the cortical tubules. In this context, fasting may alter the general metabolic activity of the body so that the metabolism of agents such as histamine, including their distribution, movement, retention, and excretion, may be adversely affected.

\section{References}

1. Bokesoy TA, Tastan S, Turker RK. Comparison of responses to histamine by constant-flow and constant-pressure perfusion methods in the rabbit isolated kidney preparation. Gen Pharmacol 1996; 27: 1047-1051.

2. Ogasawara M, Yamauchi K, Satoh Y et al. Recent Advances in Molecular Pharmacology of the Histamine Systems: Organic Cation Transporters as a Histamine Transporter and Histamine Metabolism. J Pharmacol Sci 2006; 101: 24-30.

3. Liu B, Liang H, Liu L, Zhang H. Phosphatidylinositol 4,5-bisphosphate hydrolysis mediates histamine-induced $\mathrm{KCNQ} / \mathrm{M}$ current inhibition. Am J Physiol Cell Physiol 2008; 295: 81-91.

4. D'Amore PA, Shepro D. Stimulation of growth and calcium influx in cultured bovine aortic endothelial cells by platelets and vasoactive substances. J Cell Physiol 1977; 92: 177-183.

5. Katsuki S, Murad F. Regulation of adenosine cyclic 3':5'-monophosphate and guanosine cyclic 3':5'-monophosphate levels and contractility in bovine tracheal smooth muscle. Mol Pharmacol 1977; 13: 330-341.

6. Quach TT, Duchemin AM, Rose C. 3Hglycogen hydrolysis elicited by histamine in brain slices: selective involvement of HI receptors. Mol Pharmacol 1980; 17: 301-308.

7. Laszlo V, Falus A. Yet unrevealed aspects of histamine: questions from outside-answers at inside? Semin Cancer Biol 2000; 10: 1-2.

8. Leurs R, Smit MJ, Timmerman H. Molecular pharmacological aspects of histamine receptors. Pharmacol Ther 1995; 66: 413-463.

9. De Esch IJ, Belzar KJ. Histamine H3 receptor agonists. Mini Rev Med Chem 2004; 4: 955-963.

10. Dove S, Elz S, Seifert R, Buschauer A. Structure-activity relationships of H2 receptor ligands. Mini Rev Med Chem 2004; 4: 941-954.

11. Pertz HH, Elz S, Schunack W. Structure-activity relationships of histamine H1-receptor agonists. Mini Rev Med Chem 2004; 4: 935-940.

12. Spath MM, Pavenstadt H, Fischer R, Schlunck G, Wanner C, Schollmeyer P. Effects of histamine on inositol phosphates and intracellular $\mathrm{Ca} 2+$ in human glomerular epithelial cells. Nephrol Dial Transplant 1994; 9: 758-763.

13. Henningsson SSG, Rosengren E. Distribution of histidine decarboxylase in the pregnant mouse kidney. Q J Exp Physiol Cogn Med Sci 1971; 56: 156-159.

14. Juhlin L. Determination of histamine in small biopsies and histological sections. Acta Physiol Scand 1967; 71: 30-36.

15. Heald JI, Hollis TM. Histidine decarboxylase-mediated histamine synthesis in glomeruli from rat kidneys. Am J Physiol 1976; 230: 13491353.

16. Amlal H, Chen Q, Habo K, Wang Z, Soleimani M. Fasting downregulates renal water channel AQP2 and causes polyuria. Am J Physiol Renal Physiol 2001; 280: 513-523.

17. Pennell JP, Sanjana V, Frey NR, Jamison RL. The effect of urea infusion on the urinary concentrating mechanism in protein-depleted rats. J Clin Invest 1975; 55: 399-409.

18. Gontmakher VM, Sagdullaev ZZ, Gainullin MG. Various structural aspects of the functional transformation of kidneys during adaptation to fasting. Arkh Anat Gistol Embriol 1986; 92: 90-94.

19. Ortiz A, Lorz C, Justo P, Catalán MP, Egido MP. Contribution of apoptotic cell death to renal injury. J Cell Mol Med 2001; 5: 18-32. 
20. Thornberry NA, Lazebnik Y. Caspase-s: enemies within. Science 1998; 281: 1312-1316.

21. Liu X, Zou H, Slaughter C, Wang XDFF. A heterodimeric protein that fonctions down stream of caspase-3 to trigger DNA fragmentation during apoptosis. Cell 1997; 89: 175-184.

22. Nicholson ML, Metcalfe MS, White SA et al. Comparison of the results of renal transplantation from non-heart-beating, conventional cadaveric, and living donors. Kidney Int 2000; 58: 2585-2591.

23. Yang F, Liu GS, Lu XY, Kang JL. Expression of caspase--3 in rat kidney with renal tubular damage induced by lipopolysaccharide and hypoxia. Nan Fang Yi Ke Da Xue Xue Bao 2009; 29: 2091-2093.

24. Cansu A, Giray SG, Serdaroglu A, Erdogan D, Coskun ZK, Korucuoglu U, Biri AA. Effects of chronic treatment with valproate and oxcarbazepine on ovarian folliculogenesis in rats, Epilepsia. 2008; 49: 1192-1201.

25. Schor N, Ichikawa I, Brenner BM. Mechanisms of action of various hormones and vasoactive substances on glomerular ultrafiltration in the rat. Kidney Int 1981; 20: 442-451.

26. Sedor JR, Abboud HE. Histamine receptors in isolated human glomeruli. Kidney Int 1984; 26: 144-152.

27. Brenner BM. Nephron adaptation to renal injury or ablation. Am J Physol 1985; 249: 324-337.
28. Szabo J, Devenyi I. Ultrastructural data on different type of hyperplasia and hyperfunction of the juxtaglomerular apparatus. Acta Morphol Acad Sci Hungary 1972; 20: 39-48.

29. Yang B, Jain S, Ashra SY, Furness PN, Nicholson ML. Apoptosis and Caspase--3 in Long-Term Renal Ischemia/Reperfusion Injury in Rats and Divergent Effects of Immunosuppressants. Transplantation 2006; 81 : $1442-1450$.

30. Bourgoignie JJ, Gavellas G, Martinez E, Pardo V. Glomerular function and morphology after renal mass reduction in dogs. J Lab Clin Med 1987; 109: 380-388.

31. Abboud HE, Ou SL, Velsoa JA, Shah SV, Dousa TP. Dynamics of histamine in the normal rat kidney and aminonucleoside nephrosis. J Clin Invest 1982; 69: 327-336.

32. Chansel D, Oudinet JP, Nivex MP, Ardaillou R. Histamine H2 receptors in glomeruli isolated from rat renal cortex. Biochem Pharmacol 1982; 31: 367-375.

33. Schwertschlag $\mathbf{U}$, Hackenthal H. Histamine stimulates renin release from the isolated perfused rat kidney. Arch. Pharmacol 1980; 319: 239-246.

34. Melmon KL, Rocklin RE, Roberto RE. Autacoids as modulators of the inflammatory and immune response. Am J Med 1981; 71: 100-106.

Received September 24, 2012. Accepted January 18, 2013. 